\title{
Comparison of aerosol properties retrieved using GARRLiC, LIRIC, and Raman algorithms applied to multi-wavelength lidar and sun/sky-photometer data
}

\author{
Valentyn Bovchaliuk $^{1}$, Philippe Goloub ${ }^{1}$, Thierry Podvin ${ }^{1}$, Igor Veselovskii ${ }^{2}$, Didier Tanre ${ }^{1}$, Anatoli Chaikovsky ${ }^{3}$, \\ Oleg Dubovik ${ }^{1}$, Augustin Mortier ${ }^{4}$, Anton Lopatin ${ }^{1}$, Mikhail Korenskiy ${ }^{2}$, and Stephane Victori ${ }^{5}$ \\ ${ }^{1}$ Laboratoire d'Optique Atmospherique, Lille1 University, Villeneuve d'Ascq, France \\ ${ }^{2}$ Physics Instrumentation Center of the General Physics Institute, Troitsk, Moscow Region, Russia \\ ${ }^{3}$ Institute of Physics, NAS of Belarus, Minsk, Belarus \\ ${ }^{4}$ Norwegian Meteorological Institute, Oslo, Norway \\ ${ }^{5}$ Cimel advanced monitoring, Paris, France
}

Correspondence to: Valentyn Bovchaliuk (bovchaliukv@gmail.com)

Received: 6 February 2016 - Published in Atmos. Meas. Tech. Discuss.: 9 March 2016

Revised: 3 July 2016 - Accepted: 5 July 2016 - Published: 28 July 2016

\begin{abstract}
Aerosol particles are important and highly variable components of the terrestrial atmosphere, and they affect both air quality and climate. In order to evaluate their multiple impacts, the most important requirement is to precisely measure their characteristics. Remote sensing technologies such as lidar (light detection and ranging) and sun/sky photometers are powerful tools for determining aerosol optical and microphysical properties. In our work, we applied several methods to joint or separate lidar and sun/skyphotometer data to retrieve aerosol properties. The Raman technique and inversion with regularization use only lidar data. The LIRIC (LIdar-Radiometer Inversion Code) and recently developed GARRLiC (Generalized Aerosol Retrieval from Radiometer and Lidar Combined data) inversion methods use joint lidar and sun/sky-photometer data. This paper presents a comparison and discussion of aerosol optical properties (extinction coefficient profiles and lidar ratios) and microphysical properties (volume concentrations, complex refractive index values, and effective radius values) retrieved using the aforementioned methods. The comparison showed inconsistencies in the retrieved lidar ratios. However, other aerosol properties were found to be generally in close agreement with the AERONET (AErosol RObotic NETwork) products. In future studies, more cases should be analysed in order to clearly define the peculiarities in our results.
\end{abstract}

\section{Introduction}

In situ and remote sensing measurements are the two main approaches used for aerosol observations. The former involves measurements of particles using instruments at the survey points. The latter involves measuring aerosol properties from a distance without direct interaction with particles. Remote sensing methods can be categorized into active and passive depending on the kind of instrument used. Instruments belonging to the passive category measure the modified solar radiation after interactions with particles and terrestrial radiation. One of the most common instruments in this category, a sun/sky photometer, measures both direct and diffuse solar radiation. These data can be used in inversion algorithms (Dubovik and King, 2000; Dubovik et al., 2011) to retrieve several column-integrated aerosol properties such as the aerosol optical depth (AOD), single scattering albedo (SSA), particle size distribution (SD), effective radius $\left(r_{\text {eff }}\right)$, and complex refractive index (CRI, including real (RRI) and imaginary (IRI) parts of refractive index). Instruments belonging to the active category of remote sensing measurement scattered radiation emitted by themselves; one of the most well-regarded and widely used instrument in this category is lidar (light detection and ranging). Lidar instruments are used for profiling atmospheric variables such as the temperature, pressure, humidity, wind speed and its direction, and the amount of trace gases and aerosols. The main 
advantages of lidar measurements include high vertical resolution and applicability during nighttime and in cloudy environments. Current multi-wavelength lidar observations can provide comprehensive and quantitative information regarding aerosol properties (Böckmann et al., 2005; Veselovskii et al., 2015, 2016; Nicolae et al., 2013; Granados-Muñoz et al., 2014).

Several methods, techniques, and algorithms can be used to obtain the optical and microphysical characteristics of aerosols. These methods generally use different sets of data. For instance, AERONET (AErosol RObotic NETwork) inversion code uses only sun/sky-photometer data (Dubovik and King, 2000). Similarly, the Raman technique and regularization algorithm use only lidar data (Ansmann et al., 1990; Weitkamp, 2005; Veselovskii et al., 2002). The LIRIC (LIdar-Radiometer Inversion Code) and GARRLiC (Generalized Aerosol Retrieval from Radiometer and Lidar Combined data) algorithms, in contrast, use both the sun/skyphotometer and lidar data (Lopatin et al., 2013; Chaikovsky et al., 2016). Because these methods use different datasets, they are applicable during different observational times. For instance, while the Raman technique is most suitable for nighttime observations, sun/sky photometers do not make measurements at that time. Further, the GARRLiC algorithm, which is included in the GRASP (Generalized Retrieval of Atmosphere and Surface Properties) inversion code (Dubovik et al., 2011), can separate the fine and coarse modes of aerosols, thus resulting in the retrieval of particle characteristics separately for both modes. While different methods retrieve different sets of aerosol characteristics, all of them are aimed at obtaining detailed results. The objective of our study is to discriminate and compare the common aerosol characteristics obtained through different methods.

Section 2 describes the observation sites where the measurements were carried out. This section also describes a new lidar system, called LILAS (LIlle Lidar AtmosphereS), which was used at the observation sites. Section 3 presents the methods considered in our study and discusses their potential, applicability, and the common aerosol properties that were considered for comparison. Section 4 presents three dust cases that were selected and analysed by using the algorithms described in Sect. 3. The main conclusions and perspectives are given in the last section.

\section{Observational sites and the lidar system}

The lidar system LILAS used in this work belongs to Laboratoire d'Optique Atmospherique (LOA). This system is operated at the campus of Lille University, France. The campus area is influenced mainly by urban and industrial pollutant emissions, marine aerosols, and mineral dust and aerosols from volcanic eruptions several times every year (Mortier et al., 2013). Other remote sensing and in situ instruments are also operational at this site. Among them is a lunar pho- tometer for observing AOD and Ångström exponent $(\alpha)$ values on clear nights within the half moon to full moon lunar phases. LOA is a permanent lidar site. However, for the study of Saharan dust over West Africa (SHADOW2 campaign), LILAS was moved to M'Bour city (Dakar site) in Senegal at the beginning of January 2015. The Dakar site is influenced by mineral dust during March-April and biomass burning during December-January. The two main objectives of the campaign were (i) to record the physical and chemical properties of aerosols over the regions impacted by considerable amounts of dust particles and (ii) to study the aerosol dynamics. Seven laboratories with 18 instruments took part in the campaign.

The LILAS system was assembled and setup in December 2013, and observations started in January 2014. The system is composed of a laser (Spectra-physics, INDI-40) emitting at wavelengths of 1064,532 , and $355 \mathrm{~nm}(100 \mathrm{~mJ} / 20 \mathrm{~Hz})$, a Newton telescope, a beam rotator, and a receiving module. The beam rotator can be used for near- or far-range observations by changing the overlap function. Several receiving modules were added in April 2014, and the system now consists of five elastic channels ( 355 and $532 \mathrm{~nm}$ both parallel and perpendicular for analog and photo-counting; $1064 \mathrm{~nm}$ for total analog) and three Raman channels ( $387 \mathrm{~nm}$ for analog and photo-counting; 408 and $608 \mathrm{~nm}$ for photocounting). During the SHADOW2 campaign, the vibrational Raman channel at $608 \mathrm{~nm}$ was changed to a rotational channel at $530 \mathrm{~nm}$. This rotational Raman channel showed a good and stable performance (Veselovskii et al., 2015, 2016). The system can be remotely operated and is coupled with a radar (radio detection and ranging) for reasons such as automatic discontinuation control and airplane safety.

The Lille site became an observation station of the European Aerosol Research LIdar NETwork (EARLINET) in the summer of 2014. The main goal of the network is to provide a comprehensive, quantitative, and statistically significant database on aerosol distributions. The network has some special criteria for data quality assurance, such as a telecover test, a trigger delay, dark measurements, depolarization calibration, and regular check-ups of the Rayleigh fits (Freudenthaler, 2007, 2008, 2010; Freudenthaler et al., 2016). LILAS has passed all the EARLINET tests and check-ups except for depolarization calibration, which is currently in progress.

\section{Retrieval algorithms}

Depending on the lidar characteristics, different techniques can be used for obtaining optical and microphysical properties of aerosols. All the methods and algorithms that were used for data processing are introduced in this section.

Elastic-backscatter lidar is considered to be a classic form of lidar technology (Weitkamp, 2005). This technology is based on the measurement of elastically scattered light in the backward direction. The common method that derives 
aerosol optical characteristics is the Klett method (Klett, 1981, 1985). This method is based on the relationship between the extinction and backscatter coefficients. The algorithm called BASIC (Mortier et al., 2013) based on the Klett method has been developed at LOA and is successfully implemented into routine for mono-wavelength lidar data. This algorithm retrieves an extinction coefficient profile $\left(\sigma_{\text {aer }}(z)\right)$ following an iterative procedure based on a dichotomy where the lidar ratio (LR) can vary in the range from 10 to $140 \mathrm{sr}$. The procedure ends when the integral of the extinction profile is close to the AOD measured by a sun/sky photometer within $\triangle \mathrm{AOD}=0.01$ accuracy.

The Raman lidar technique is a widely known technique in the lidar community for obtaining aerosol optical properties $(\sigma, \beta, \mathrm{LR})$ (Ansmann et al., 1990). This technique is based on the scattering of incident lidar light with photon energy shifts due to vibrational or rotational modes of the molecules. It is mostly used at nighttime when the signal-to-noise ratio is the highest, owing to the absence of sunlight scattered into the field of view of the lidar. Assuming that the aerosol extinction coefficient depends on the wavelength through $\alpha$, the former can be found calculated as (Weitkamp, 2005)

$$
\sigma_{\text {aer }}\left(\lambda_{\mathrm{L}}, z\right)=\frac{\frac{\mathrm{d}}{\mathrm{d} z}\left[\ln \frac{N(z)}{z^{2} P(z)}\right]-\sigma_{\mathrm{mol}}\left(\lambda_{\mathrm{L}}, z\right)-\sigma_{\mathrm{mol}}\left(\lambda_{\mathrm{R}}, z\right)}{1+\left(\frac{\lambda_{\mathrm{L}}}{\lambda_{\mathrm{R}}}\right)^{\alpha}},
$$

where $P(z)$ is the power received at the Raman wavelength $\lambda_{\mathrm{R}}$ from distance $z, N(z)$ is the molecule number density, $\sigma_{\mathrm{mol}}\left(\lambda_{\mathrm{L}}, z\right)$ and $\sigma_{\mathrm{mol}}\left(\lambda_{\mathrm{R}}, z\right)$ are the extinction coefficients due to absorption and Rayleigh scattering by atmospheric molecules for emitting lidar and Raman wavelengths, respectively, and $\alpha$ is the Ångström exponent. The aerosol backscatter coefficient can be calculated from the ratio of the elastic signal to Raman signal by using a coefficient determined at a reference point where no aerosol is expected.

A variety of methods can be used to retrieve aerosol microphysical properties using lidar data. They can be divided into three main groups (Weitkamp, 2005). The methods belonging to the first group combine measurements from several instruments that provide enough information to retrieve aerosol microphysical properties. For such methods, the collocation of measurements by different instruments in space and time is necessary. The LIRIC algorithm belongs to this group; it successfully retrieves height-resolved aerosol optical and microphysical properties separately for fine and coarse modes (Chaikovsky et al., 2012, 2016; Wagner et al., 2013; Granados-Muñoz et al., 2014). The algorithm uses AERONET inversion products such as column volume concentration, volume-specific backscatter, and extinction coefficients as a priori information (Chaikovsky et al., 2016). The specific products include backscatter $(\beta)$, extinction $(\sigma)$, and volume concentration $(V)$ profiles, Ångström ex- ponent $(\alpha)$ values, and LR and depolarization $(\delta)$ ratios. A deeper synergy between the lidar and sun/sky-photometer data is achieved in the GARRLiC algorithm developed at LOA (Lopatin et al., 2013). GARRLiC inverts the coincident lidar and sun/sky-photometer radiometric data simultaneously. The other marked distinction between GARRLiC and LIRIC is the inversion of two distinct aerosol modes, which makes it possible to retrieve aerosol optical and microphysical properties independently for both the fine and coarse modes. Such differences in the algorithms can influence the results obtained by the two systems. The GARRLiC method is based on the Dubovik inversion code (Dubovik and King, 2000; Dubovik et al., 2011), which has been previously used for processing AERONET data. The synergistic retrieval is expected to improves aerosol retrieval properties; the lidar observations are expected to improve the observations of the columnar properties of aerosols in the backscattering direction, and sun/sky photometers provide information on aerosol properties, such as their amount or type, required for lidar retrievals without making assumptions based on climatological data.

GARRLIC has been designed to provide two independent vertical concentration profiles for the fine and coarse modes of aerosols, since in most cases, aerosols are believed to consist of two modes. However, it works for single mode inversions as well. In such cases, a single value for the total amount of particles is retrieved. The algorithm is quite flexible in this regard; single or double mode inversion can be chosen by the user. Further, single- or multi-wavelength lidar data can be used. In the case of multi-wavelength lidar data, aerosol properties can be retrieved for fine and coarse modes separately or together for the total amount of particles. In the case of single-wavelength lidar data, the aerosol properties can be retrieved only for the total amount of aerosols. Depending on the different configurations of single or double mode inversion employed and the use of single- or multiwavelength lidar data, different sets of aerosol parameters can be retrieved (see Fig. 1). Spectral information from multiple wavelengths is used to distinguish the contribution of fine and coarse aerosol modes. It should be noted that aerosol events characterized mainly by one type of aerosols or a mixture of particles similar in size (aerosol types are not distinguished inside the mode of particles) should be retrieved by using the configuration of single mode inversion.

As for the second group of methods, optical properties ( $\beta$ and $\sigma$ profiles) are calculated using Mie theory and are compared with the results obtained by using the Raman technique (Wandinger et al., 1995; Barnaba and Gobbi, 2001). In these methods, aerosol microphysical properties such as SD and CRI are assumed as a priori information. Such methods are used in case of atmospheric layers with single, well-known type of particles. For instance, such methods can characterize the particles of polar stratospheric clouds, volcanic ejecta, and some stratospheric particles. However, owing to the presence of a variety of particles and rapid changes in the atmo- 


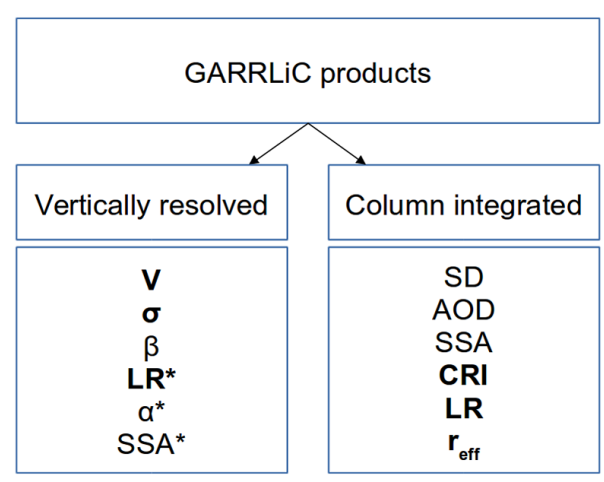

Figure 1. GARRLiC products derived by using single (unmarked) or double (both unmarked and marked *) mode inversion. The latter can be applied only to multi-wavelength lidar data. Common properties, which are compared in this work, retrieved using GARRLiC, LIRIC, and Raman and regularization are indicated by bold font.

spheric conditions, such methods are not applicable to the troposphere.

The third group consists of mathematical approaches that use $\beta$ and $\sigma$ coefficient profiles at multiple wavelengths (only lidar measurements). Such methods were developed from the methods of the second group, but they require a lower number of a priori parameters (Müller et al., 1999; Veselovskii et al., 2002, 2004; Shcherbakov, 2007). The algorithm called inversion with regularization developed by (Veselovskii et al., 2002, 2004, 2010b) has also been considered in this work. A simplified set of lidar data (three backscatter (355, 532, and $1064 \mathrm{~nm})$ and two extinction (355 and $532 \mathrm{~nm}$ ) coefficients - the so-called $3 \beta+2 \sigma$ dataset) allows the retrieval of the main aerosol microphysical properties (Veselovskii et al., 2005). Aerosol optical properties that are required for the regularization algorithm can be derived using the Raman technique. The main aerosol microphysical products of the regularization algorithm are the CRI, $r_{\text {eff }}$, number, surface area, and volume concentrations (Veselovskii et al., 2002, 2010b).

These groups of retrieval methods use different types of measurements and, also, different amounts of information. For instance, while regularization uses the $3 \beta+2 \sigma$ set of optical data, AERONET uses up to $\sim 30$ measurements (direct and diffuse almucantar measurements) at each wavelength. Hence, it is important to compare the particle properties retrieved with these methods for these different groups. If different algorithms retrieve similar aerosol properties, it will mean that they are in agreement and can complement each other for data processing during long-term day-night observations.

Aerosol characteristics that are common to LIRIC, GAR$\mathrm{RLiC}$, and regularization algorithms are $\sigma, \mathrm{LR}, \mathrm{CRI}, V$, and $r_{\text {eff. }}$ The challenging issue here is that no perfectly coincident measurements exist that can be used by these algorithms. The standard Raman technique preferably uses lidar measurements during nighttime, while the sun/sky photometers require sunlight. Consequently, for a comparison of the retrieved aerosol properties by using the GARRLiC/LIRIC and regularization algorithms, early morning or late evening data under stable atmospheric conditions should be selected. Three events fulfilling these requirements were selected and analysed.

\section{Applications}

Several dust events were selected from the LILAS measurements over the Lille and Dakar sites. These days had moderate $(\mathrm{AOD} \simeq 0.5$ at $440 \mathrm{~nm})$ to high $(\mathrm{AOD} \simeq 1.5$ at $440 \mathrm{~nm}$ ) aerosol loads. Back trajectories (Draxler and Rolph, 2015; Rolph, 2015) and the NMMB/BSC-Dust model (Nonhydrostatic Multiscale/Barcelona Supercomputing Centre Dust model (Pérez et al., 2011; Haustein et al., 2012) confirmed the origin of mineral dust from Sahara and showed the source locations. In the case of local dust events, the backtrajectory analysis was not used. More details and results of the comparison of each event are presented below.

The AERONET products are presented herein for comparison. As it is used as a priori information for the LIRIC algorithm, the LRs retrieved by LIRIC are presented along with the AERONET characteristics (marked by ** in Tables 2 and 3 ). Mass concentration profiles were obtained simply by multiplying the volume concentration profiles, $V$, with the mass density of fine and coarse mode particles. The densities of the fine and coarse modes are 1.5 and $2.6 \mathrm{~g} \mathrm{~cm}^{-3}$, respectively (Binietoglou et al., 2015; Ansmann et al., 2011, 2012; Haustein et al., 2012). This density for the coarse mode is also considered in the NMMB/BSC-Dust model.

The GARRLiC and LIRIC algorithms produce uncertainties with the retrieved aerosol properties. For the GARRLiC algorithm, systematic and random errors are presented. For the LIRIC algorithm, only the dispersion of aerosol volume concentration profiles is presented. This work presents only the uncertainties regarding the directly retrieved aerosol properties. Uncertainties on the derived aerosol properties $(\sigma$, LR, SSA profiles) are not presented due to their high values as derived by GARRLiC (rough estimations were about $100 \%$ and more). The uncertainties in the volume concentration profiles retrieved using the regularization algorithm are assumed to be about $20 \%$ (Veselovskii et al., 2004, 2005, 2016).

As this work mainly deals with mineral dust sometimes mixed with marine aerosol particles, it will be useful to consider the particle properties obtained from previous studies. According to (Weitkamp, 2005), (Müller et al., 2005), (Müller et al., 2013), (Pitari et al., 2015), and (Dubovik et al., 2002), the typical values of $r_{\text {eff }}$ for desert dust vary within the range of 1.2-2.4 $\mu \mathrm{m}$, and $r_{\text {eff }}$ for the coarse mode of sea salt is close to $2.7 \mu \mathrm{m}$ (Dubovik et al., 2002). The SSA for dust particles increases from 0.80 to 0.99 in the ultraviolet-near- 
infrared range (Collaud Coen et al., 2004; Dubovik et al., 2002). The SSA for marine aerosols is high, at $\sim 0.98$, and the value remains stable at all wavelengths. The RRI varies from 1.5 to 1.6 for dust particles and is close to 1.36 for marine particles. The IRI decreases from 0.02 to 0.001 in the ultraviolet-near-infrared range for dust particles and is close to 0.001 for marine particles. For Saharan dust, the LR varies within the range of 50-80 sr at a wavelength of $532 \mathrm{~nm}$, and it is significantly lower, at 20-35 sr, for marine particles (Weitkamp, 2005; Müller et al., 2007, 2010; Groß et al., 2011). The depolarization ratio is high, being close to 30-35\% for dust particles, whereas marine particles have a significantly lower $\delta$, i.e. close to $5 \%$ (Freudenthaler et al., 2009; Groß et al., 2011).

\subsection{Analysis of a moderate dust event in Lille on 30 March 2014}

The dust event detected over Lille on 30 March 2014 was characterized as heavy for Lille site in terms of the aerosol load (AOD $440 \mathrm{~nm} \approx 0.52 ; \alpha \approx 0.27$ for $440 / 870 \mathrm{~nm}$ ). The back-trajectory analysis showed that aerosols, which were located in the altitude range of 3 to $6 \mathrm{~km}$, had their origin in the Saharan region (Fig. 2), and aerosols located up to $2 \mathrm{~km}$ travelled from south and south-east France. According to lidar measurements, very thin and homogeneous cirrus clouds with negligible effect on AOD were present at $11 \mathrm{~km}$. Cross-examination was done using almucantar sky radiance measurements in order to prevent cloud contamination. The relative deviation between the left/right sky radiance measurements in almucantar geometry was found to be less than $20 \%$. Cirrus clouds were identified by neither us nor AERONET criteria (Holben et al., 2006); the exact time of the sun/sky-photometer measurements was 07:42 UTC. The NMMB/BSC-Dust model (operated by the Barcelona Supercomputing Center, www.bsc.es/projects/earthscience/ NMMB-BSC-DUST/) confirmed dust emissions over Algeria that travelled towards Lille (Fig. 3).

The configuration of LILAS was changed from three channels (355 $\mathrm{nm}$ parallel and perpendicular and $532 \mathrm{~nm}$ total) to eight channels ( 355 and $532 \mathrm{~nm}$ parallel and perpendicular; 387, 408, 608, and $1064 \mathrm{~nm}$ total) in April 2014. Hence, the Saharan dust event could not be analysed by the Raman and regularization algorithms. Unfortunately, depolarization calibration of $355 \mathrm{~nm}$ have not been done for the event. Hence, only data at $532 \mathrm{~nm}$ channel were used for analysis. LIRIC inversion had not been applied to this event. Consequently, only the GARRLiC and BASIC algorithms were considered in our analysis. Single mode GARRLiC inversions were considered due to only lidar signal at $532 \mathrm{~nm}$. The lidar elevation angle during the measurements was $56^{\circ}$.

Aerosol properties retrieved by the GARRLiC and BASIC algorithms and AERONET products are presented in Table 1 and Figs. 4 and 5. The columnar-integrated GARRLiC SSA values increase with the wavelength, i.e. from

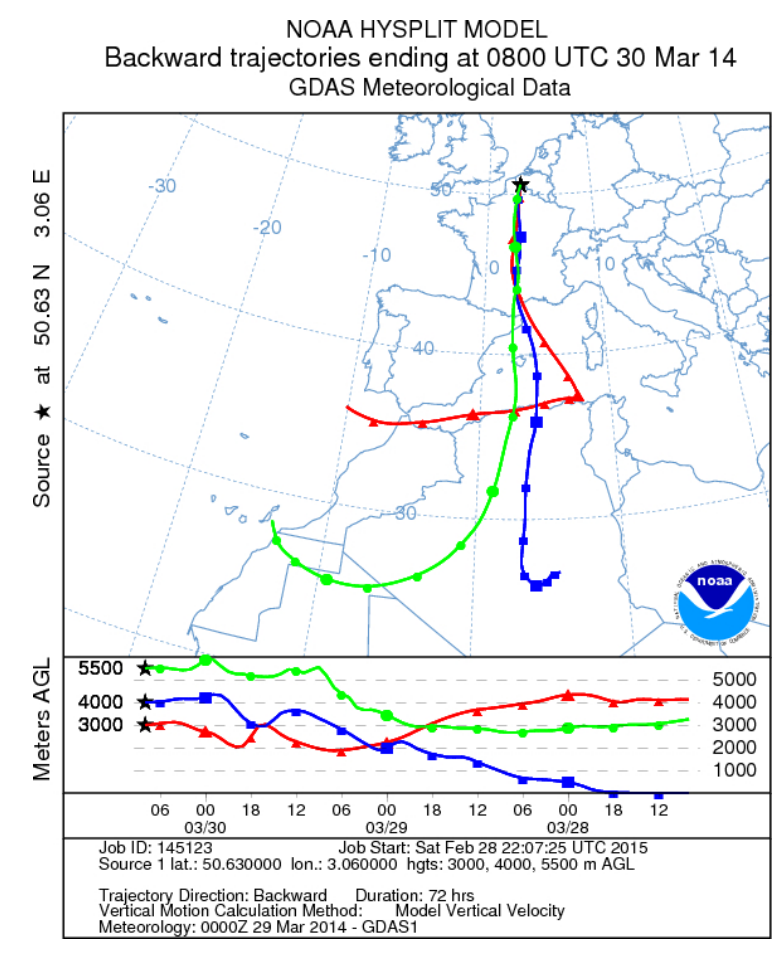

Figure 2. Backward trajectories of air masses observed over Lille during the morning of 30 March 2014.

$0.94 \pm 0.01$ at $440 \mathrm{~nm}$ to $0.98 \pm 0.01$ at $1020 \mathrm{~nm}$. The RRI is close to $1.50 \pm 0.02$, the IRI decreases from $0.002 \pm 0.001$ to $0.001 \pm 0.001$. The CRI values retrieved by GARRLiC are in agreement with the AERONET retrievals. The GARRLiC LR values are lower in comparison to the ones retrieved by AERONET at wavelengths of 440 and $532 \mathrm{~nm}$, while they are almost equal at others. The BASIC LR value at $532 \mathrm{~nm}$ are close to the value interpolated by AERONET values. The effective radius for the coarse mode of particles is high and is close to $2.0 \mu \mathrm{m}$, and the $r_{\text {eff }}$ for the fine mode is close to the value of urban particles.

The size distribution (see Fig. 4) clearly shows the predominance of coarse mode particles with two maxima. The first one with lower radii likely indicates dust particles, and the second one with larger radii also indicates dust particles or can refer to the particles of thin cirrus clouds (Trouillet and Flamant, 1999; Heymsfield and Platt, 1984). The sphericity parameter retrieved by GARRLiC is in agreement with the one from AERONET, both being close to $1 \%$. The extinction profiles retrieved by BASIC and GARRLiC are close (Fig. 5).

The back-trajectory analysis indicates two layers. This mixture of dust and some fine particles results in lower LR and CRI and higher SSA (at 440 and $532 \mathrm{~nm}$ ) values than for aerosols from mineral dust only (Balis et al., 2004; Giannakaki et al., 2010; Petzold et al., 2011). Consequently, if the higher layer consisted of mineral dust particles, it is possible to assume that lower aerosol layer with lower LR, 
Table 1. Aerosol properties retrieved by GARRLiC, BASIC, and AERONET. The LR values marked by $* *$ were linearly interpolated to lidar wavelength. The abbreviations $\mathrm{f}, \mathrm{c}$, and $\mathrm{t}$ correspond to fine, coarse, and total aerosol modes, respectively (AOD $440 \mathrm{~nm} \approx 0.52 ; \alpha \approx 0.27$ for $440 / 870 \mathrm{~nm})$.

\begin{tabular}{|c|c|c|c|c|c|c|c|c|c|}
\hline \multirow[b]{2}{*}{$\lambda(\mathrm{nm})$} & \multicolumn{5}{|c|}{ GARRLiC } & \multirow{2}{*}{$\begin{array}{l}\text { BASIC } \\
\text { LR (sr) }\end{array}$} & \multicolumn{3}{|c|}{ AERONET } \\
\hline & $r_{\text {eff }}(\mu \mathrm{m})$ & Sph \% & RRI & IRI & LR (sr) & & RRI & IRI & $\mathrm{LR}(\mathrm{sr})$ \\
\hline 440 & & & 1.50 & 0.002 & 53 & & 1.48 & 0.002 & 57 \\
\hline 532 & f: 0.1 & & 1.50 & 0.002 & 48 & 53 & & & $52 * *$ \\
\hline 675 & c: 2.0 & $1 \%$ & 1.51 & 0.001 & 43 & & 1.52 & 0.001 & 43 \\
\hline 870 & $\mathrm{t}: 0.9$ & & 1.50 & 0.001 & 45 & & 1.51 & 0.001 & 43 \\
\hline 1020 & & & 1.51 & 0.001 & 45 & & 1.51 & 0.001 & 43 \\
\hline
\end{tabular}

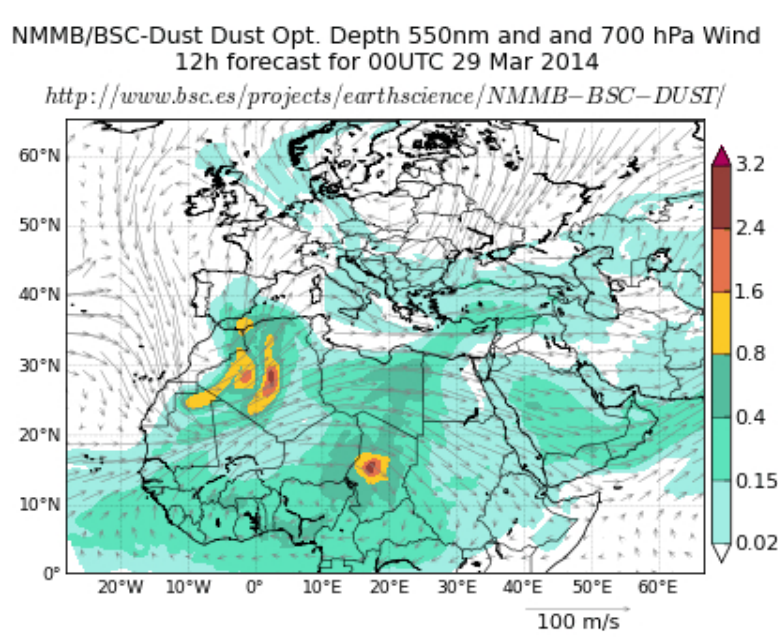

Figure 3. Dust event over Algeria on 29 March 2014.

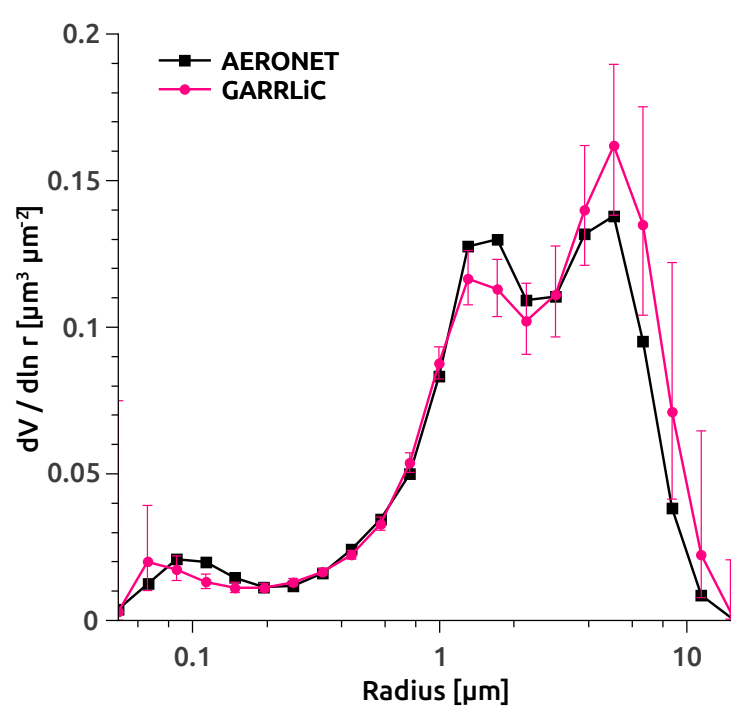

Figure 4. Volume size distribution retrieved by GARRLiC (pink) and AERONET (black) on 30 March 2014 (07:40 UTC) in Lille (AOD $440 \mathrm{~nm} \approx 0.52 ; \alpha \approx 0.27$ for $440 / 870 \mathrm{~nm}$ ).

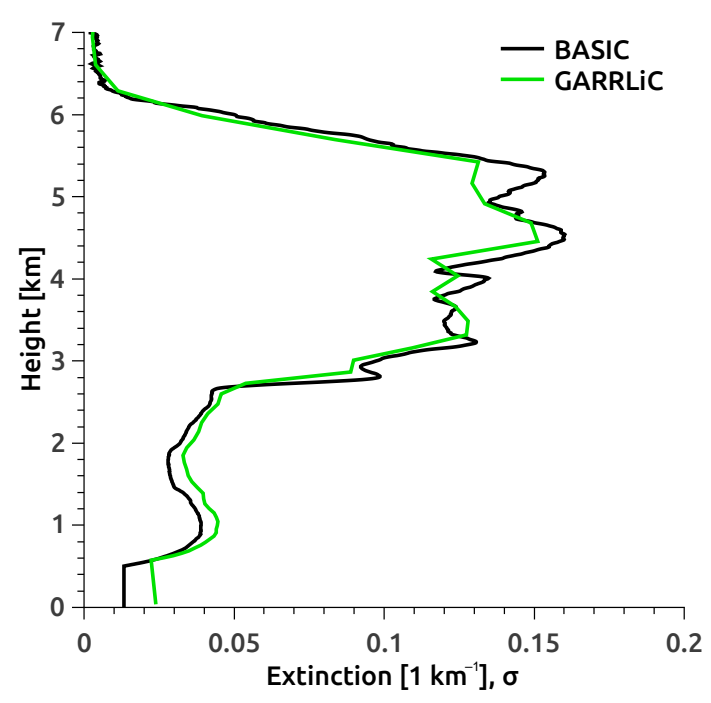

Figure 5. Aerosol extinction profiles at a wavelength $532 \mathrm{~nm}$ retrieved by the GARRLiC (green) and the BASIC (black) algorithms for dust event over Lille on 30 March 2014.

CRI, higher SSA and $r_{\text {eff }}$ of fine mode close to $0.1 \mu \mathrm{m}$ would consist of urban particles (Dubovik et al., 2002; Weitkamp, 2005). Unfortunately, no mass concentration profiles could be obtained by the NMMB/BSC-Dust model.

\subsection{Analysis of a heavy dust event in Dakar on 29 March 2015}

The second event considered in this work was also a dust event, but it occurred over the Dakar site during the SHADOW2 campaign. Three time ranges were selected for the analysis. Daytime data from 15:50 to 19:00 were selected for the Raman technique. For the GARRLiC and LIRIC algorithms, lidar signals were averaged for $20 \mathrm{~min}$ at the time of measurement by the sun/sky photometer (16:49 UTC). A third data range was selected for the regularization and Raman methods from 23:30 to 01:10 during nighttime measurements. All aerosols were found in the boundary layer for all time ranges. During the daytime measurements, the altitude of the boundary layer was $2.5 \mathrm{~km}$, and it came down to 

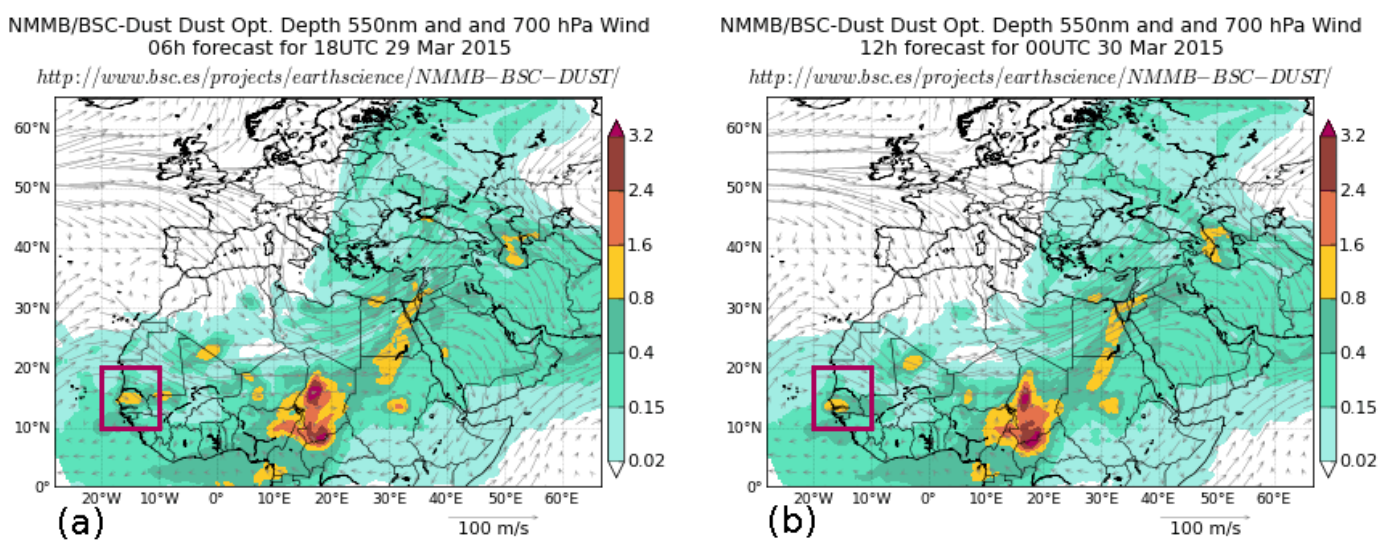

Figure 6. NMMB/BSC-Dust model over Africa and Europe on 29 March 2015. AOD values forecasted by the model ranged from 0.8 to 1.6 at 550 nm. (a) 18:00 UTC, 29 March; (b) 00:00 UTC, 30 March.

$2 \mathrm{~km}$ at night. The daytime event was characterized by a high aerosol load (AOD $440 \mathrm{~nm} \approx 1.35 \pm 0.20 ; \alpha \approx-0.04 \pm 0.01$ for $440 / 870 \mathrm{~nm}$ ), and the nighttime event was characterized by a lower aerosol load (AOD $440 \mathrm{~nm} \approx 0.83 \pm 0.03 ; \alpha \approx$ $0.08 \pm 0.02$ for $440 / 870 \mathrm{~nm}$ ). The NMMB/BSC-Dust model showed a local dust event over the Dakar site with an AOD range of $0.8-1.6$ at the $550 \mathrm{~nm}$ wavelength (Fig. 6) for both day- and nighttime measurements. A wind lidar instrument was installed on the site during the SHADOW2 campaign (Wang et al., 2014), and it captured vertically resolved wind speeds and the direction of wind at the site for up to $2 \mathrm{~km}$. The lidar data showed the wind direction to be north-northeast with a speed of 5 to $10 \mathrm{~m} \mathrm{~s}^{-1}$ in the full altitudinal range for the daytime measurements; the wind direction was northeast with a speed of 10 to $15 \mathrm{~m} \mathrm{~s}^{-1}$ in the altitudinal range of up to $1.5 \mathrm{~km}$, and lower speeds of 5 to $10 \mathrm{~m} \mathrm{~s}^{-1}$ were present in upper altitudes for the nighttime measurements. Therefore, while presumably the atmospheric conditions in terms of aerosol types should have remained the same during the event, the aerosol load decreased over the day- to nighttime measurement time frame. Also, the presence of marine particles was not expected because of the lower wind speeds and their northwardly direction during the day.

The aerosol properties retrieved by the GARRLiC and regularization algorithms for the day- and nighttime measurements, respectively, are presented in Table 2.

Single mode GARRLiC inversions were considered and performed in this event because of the huge predominance of coarse mode particles. The effective radius value is high and close to 1.9 during the daytime and decreases to $1.1 \mu \mathrm{m}$ at night. The RRI values are high, being close to $1.58 \pm 0.02$ during the daytime measurements; then, values become lower and close to $1.53 \pm 0.05$ at night. The IRI values decrease from $0.003 \pm 0.002$ to $0.002 \pm 0.001$ in the UV-nearinfrared range during the daytime and are higher at all wavelengths and close to $0.010 \pm 0.005$ at night. For both the day and night cases, the Ångström exponent is close to 0. Re- garding absorption, the SSA values obtained by GARRLiC increase from $0.87 \pm 0.02$ to $0.97 \pm 0.01$ in the UV-nearinfrared range. The daytime LR values are similar at $532 \mathrm{~nm}$, whereas the ones retrieved by GARRLiC are much lower. The LR values at $355 \mathrm{~nm}$ during the daytime measurements differ for all the algorithms, being close to 57,82 , and $37 \mathrm{sr}$ for the Raman, LIRIC, and GARRLiC algorithms, respectively. The Raman LR values slightly increase from $\sim 53$ to $\sim 58 \mathrm{sr}$ at $532 \mathrm{~nm}$, and it significantly increases from $\sim 57$ to $\sim 70 \mathrm{sr}$ at $355 \mathrm{~nm}$ over the day- to nighttime measurement time frame. Such a behaviour could be explained by the influence of marine aerosols during daytime. However, the depolarization ratio (Fig. 10) shows that there was at most very little contribution of marine aerosol during daytime. Hence, such a behaviour of retrieved aerosol properties points to inconsistency between the different methods.

It was observed that the IRI, SSA, SD, and $r_{\text {eff }}$ retrieved by GARRLiC were in good agreement with AERONET products. However, RRI values and parameter of particle sphericity differed. While the AERONET RRI is equal to 1.53 and the sphericity is equal to $0 \%$, the RRI retrieved by GARRLiC is close to 1.58 and the sphericity is $\sim 20 \%$. The differences in the LR values are presented in Table 2 and are discussed above.

Figure 7 shows that the SD values obtained from GARRLiC and AERONET are in good agreement. Figure 8 presents the aerosol volume concentrations, $V$, retrieved with the GARRLiC, LIRIC, and regularization algorithms. Because of the use of single mode inversion by GARRLiC, only the overall $V$ profile was obtained; however, the LIRIC algorithm provided both fine and coarse mode volume concentrations. Because of a high background noise, the regularization algorithm was not applied to daytime measurements; only nighttime $V$ is presented with this algorithm. The GARRLiC and LIRIC volume concentrations are in good agreement. Unfortunately, obtaining close $V$ values using GARRLiC, LIRIC, and regularization algorithms between the day- and 
Table 2. Aerosol properties during the dust event over the Dakar site on 29 March 2015. Here and further, the LR values marked by ** were retrieved by using the LIRIC algorithm. Only the values given for all the wavelengths refer to the column-integrated property. Day: AOD $440 \mathrm{~nm} \approx 1.35 \pm 0.20 ; \alpha \approx-0.04 \pm 0.01$. Night: AOD $440 \mathrm{~nm} \approx 0.83 \pm 0.03 ; \alpha \approx 0.08 \pm 0.02$.

\begin{tabular}{|c|c|c|c|c|c|c|c|c|c|c|c|}
\hline \multirow[b]{2}{*}{$\lambda(\mathrm{nm})$} & \multicolumn{5}{|c|}{ GARRLiC } & \multirow{2}{*}{$\begin{array}{l}\text { AERONET } \\
\text { LR (sr) }\end{array}$} & \multirow{2}{*}{$\begin{array}{l}\text { Raman (day) } \\
\text { LR (sr) }\end{array}$} & \multicolumn{4}{|c|}{ Raman and regularization (night) } \\
\hline & $r_{\text {eff }}(\mu \mathrm{m})$ & Sph \% & RRI & IRI & LR (sr) & & & $r_{\text {eff }}(\mu \mathrm{m})$ & RRI & IRI & $\mathrm{LR}(\mathrm{sr})$ \\
\hline 355 & & & 1.59 & 0.003 & 37 & $82 * *$ & $\sim 57$ & & & & $\sim 70$ \\
\hline 440 & & & 1.59 & 0.003 & 33 & 74 & & & & & \\
\hline 532 & f: 0.2 & & 1.59 & 0.002 & 28 & $58 * *$ & $\sim 53$ & & & & $\sim 58$ \\
\hline 675 & c: 2.2 & $20 \%$ & 1.58 & 0.002 & 25 & 43 & & 1.1 & 1.53 & 0.010 & \\
\hline 870 & $\mathrm{t}: 1.9$ & & 1.57 & 0.002 & 24 & 37 & & & & & \\
\hline 1020 & & & 1.56 & 0.002 & 22 & 35 & & & & & \\
\hline 1064 & & & 1.56 & 0.002 & 22 & $34 * *$ & & & & & \\
\hline
\end{tabular}

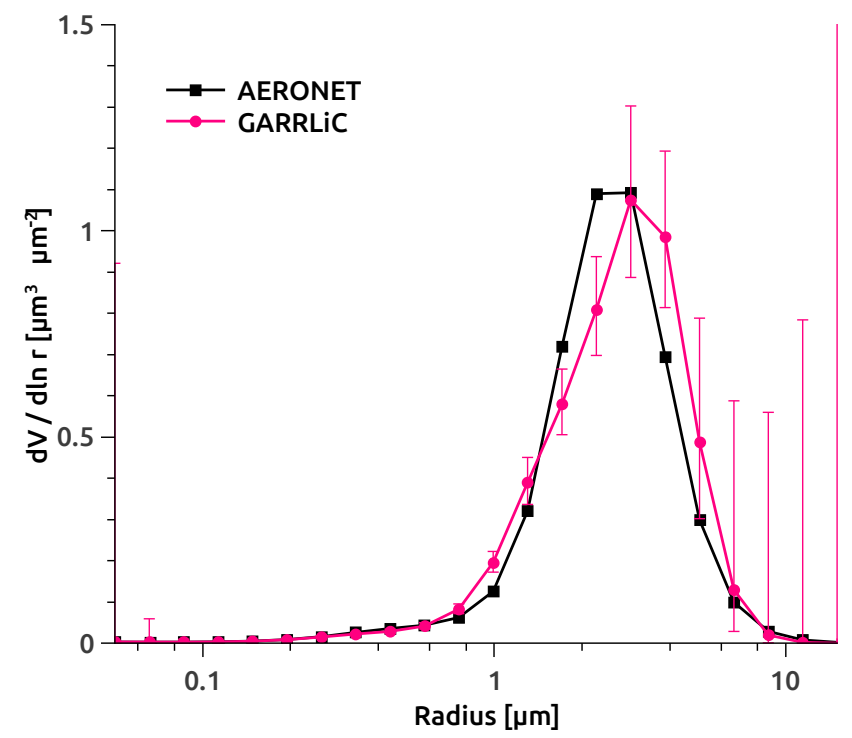

Figure 7. GARRLiC (pink) and AERONET (black) SD on 29 March 2015 (16:49 UTC) over the Dakar site (AOD $440 \mathrm{~nm} \approx$ $1.35 \pm 0.20 ; \alpha \approx-0.04 \pm 0.01)$.

nighttime is not possible because of a significant decrease in the AOD values. The relative uncertainty in $V$ obtained from the regularization method was expected to be about $20 \%$; the GARRLiC and LIRIC uncertainties are plotted in Fig. 8.

The extinction profiles (Fig. 9) at all the wavelengths were found to be in reasonable agreement. The nighttime values of $\sigma$ are lower in accordance with the lower AOD values. The top boundary of the dust layer decreases from $2.5 \mathrm{~km}$ during the day to $2 \mathrm{~km}$ at night. The GARRLiC extinction profiles are much smoother because lidar signals were reduced by averaging into 60 points during the data preparation phase. The daytime Raman LR values (Fig. 10) increase with altitude and, therefore, correct $\sigma$ profiles; however, GARRLiC and LIRIC retrieved only the column-integrated LRs in this case (GARRLiC retrieved vertically resolved LRs in the case of fine and coarse modes inversion). The particle depolar-
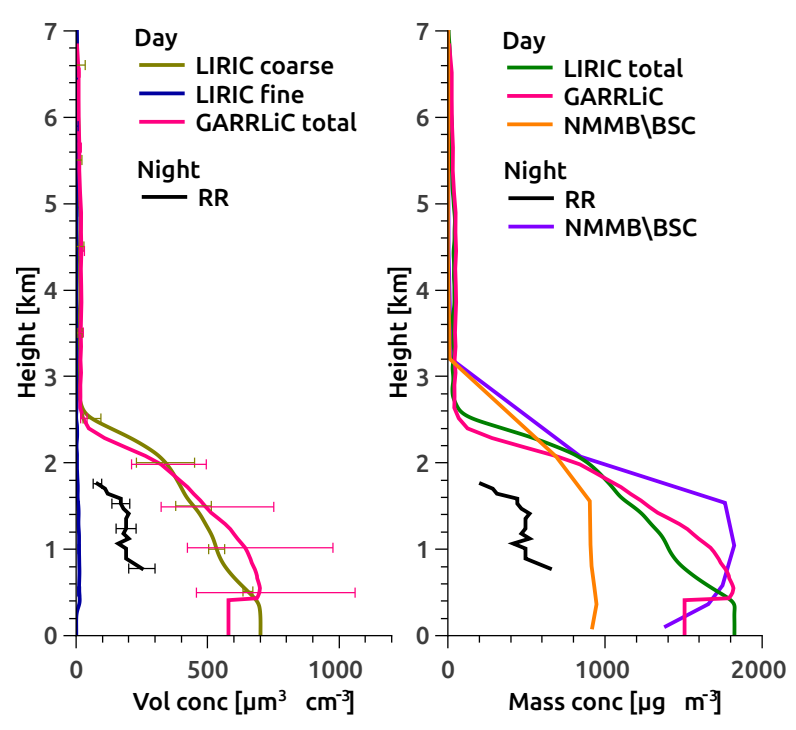

Figure 8. Volume (Vol conc) and mass (Mass conc) concentration profiles for an event over the Dakar site on 29 March 2015. The abbreviation RR corresponds to $V$ retrieved by using Raman and regularization algorithms.

ization, presented in Fig. 10, is lower during daytime (close to $29 \%$ ) and higher at nighttime when no marine particles are expected (close to $34 \%$ ). These LRs and particle depolarization values are common for mineral dust, especially at nighttime. The $r_{\text {eff }}$ profile retrieved by regularization is close to $1.1 \mu \mathrm{m}$ at the $0.9-1.6 \mathrm{~km}$ altitudinal range, and higher values up to $1.4 \mu \mathrm{m}$ were observed below $0.9 \mathrm{~km}$, whereas lower values close to 0.8 were observed above $1.6 \mathrm{~km}$. The regularization CRI profiles are stable at all altitudes; the averaged values are presented in Table 2 as column-integrated values. The $\alpha^{\text {ext }}$ profile for $355 / 532 \mathrm{~nm}$ is close to 0 at all altitudes.

For the comparison with NMMB/BSC-Dust model, the mass concentration profiles were obtained (Fig. 8). To keep the figure clear, uncertainties of mass concentration profiles are not presented. In the case of GARRLiC because of high 


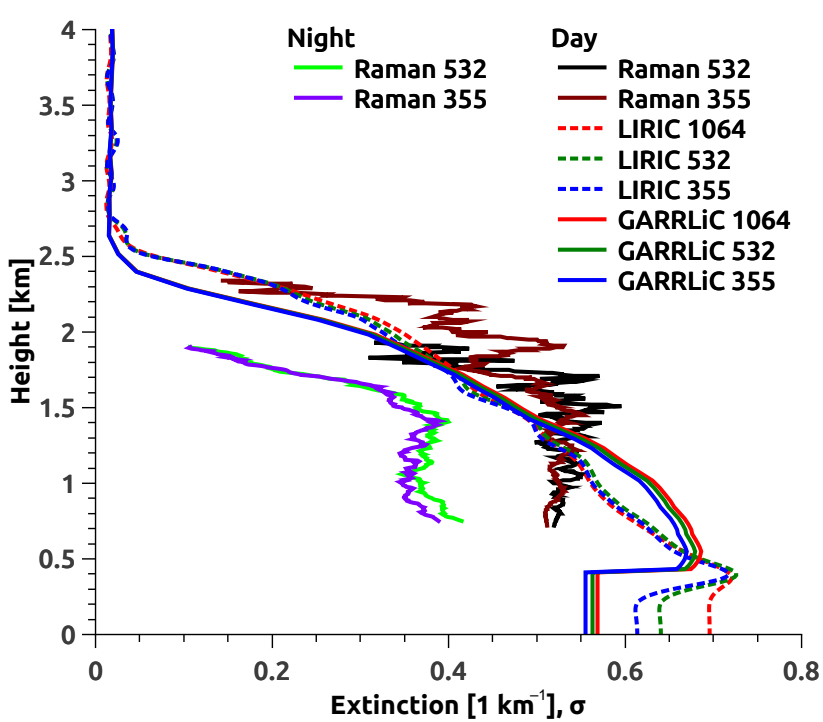

Figure 9. Raman, LIRIC, and GARRLiC extinction profiles during the day (AOD $440 \mathrm{~nm} \approx 1.35 \pm 0.20 ; \alpha \approx-0.04 \pm 0.01$ ) and night (AOD $440 \mathrm{~nm} \approx 0.83 \pm 0.03 ; \alpha \approx 0.08 \pm 0.02$ ) on 29 March 2015 .

predominance of coarse aerosol mode, particle density was taken to be equal to $2.6 \mathrm{~g} \mathrm{~cm}^{-3}$. In the case of LIRIC, both particle densities 1.5 and $2.6 \mathrm{~g} \mathrm{~cm}^{-3}$ were taken for fine and coarse aerosol modes respectively. To keep the figure clear and similar to other parameters, only total LIRIC values are presented in Fig. 8. The mass concentration profiles obtained by GARRLiC and LIRIC algorithms are $1280 \pm 500 \mu \mathrm{g} \mathrm{m}^{-3}$ and $1170 \pm 180 \mathrm{\mu g} \mathrm{m}^{-3}$ respectively at $1.5 \mathrm{~km}$, which is slightly higher in comparison with the NMMB/BSC-Dust model result $\left(\sim 900 \mu \mathrm{g} \mathrm{m}^{-3}\right)$. The nighttime mass concentration is close to $500 \pm 100 \mu \mathrm{g} \mathrm{m}^{-3}$, whereas the modelled value is close to $1700 \mu \mathrm{g} \mathrm{m}^{-3}$ at the same altitude of $1.5 \mathrm{~km}$.

\subsection{Analysis of a heavy dust event in Dakar on 10 April 2015}

The third and the last dust event considered in our study was observed on 10 April 2015 over Dakar (11 days later). Three time ranges were selected for the analysis: the first two during daytime (15:00-19:00 for Raman and 16:0116:19 for GARRLiC and LIRIC) and the third during nighttime (21:00-04:00 on 11 April 2015 for regularization). The atmospheric conditions were stable, but the height of the aerosol layer containing almost all the aerosols increased from 3 to $4.5 \mathrm{~km}$ from the day- to nighttime measurements. The daytime event was characterized by a high aerosol load (AOD $440 \mathrm{~nm} \approx 1.53 \pm 0.04 ; \alpha \approx 0.02 \pm 0.01$ for $440 / 870 \mathrm{~nm}$ ). Unfortunately, there were no lunar-photometer measurements because of the lunar phase. However, AOD derived by the integration of the $\sigma$ profile obtained by the Raman method at $532 \mathrm{~nm}$ wavelength is equal to 0.83 . It should be noted that such an estimation of AOD does not

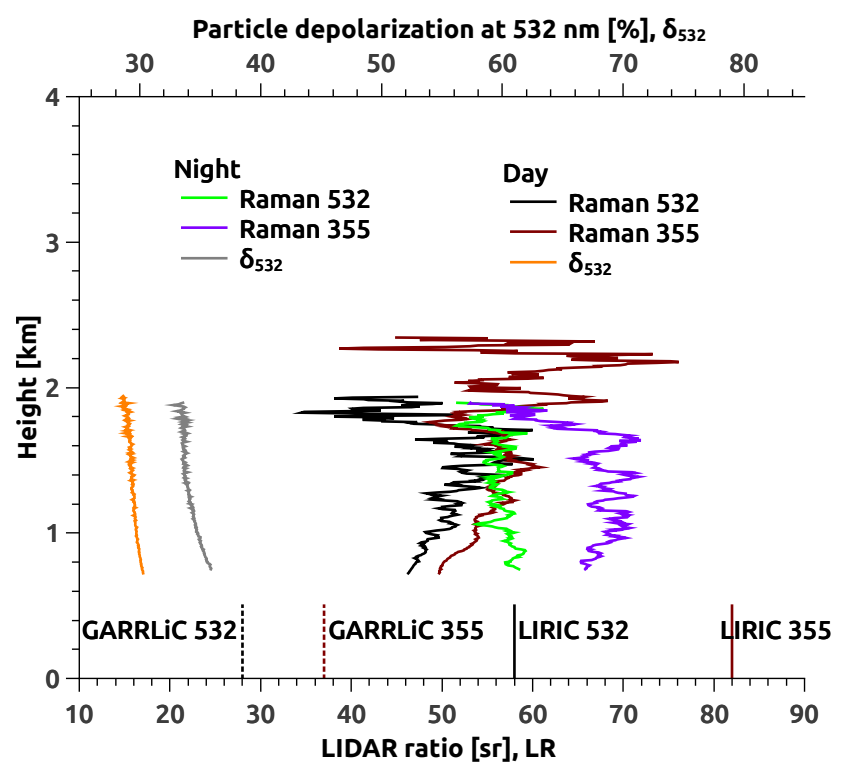

Figure 10. Lidar ratio and depolarization ratio during day- and nighttime measurements for an event on 29 March 2015 over the Dakar site. GARRLiC and LIRIC LR column-integrated values are shown at the beginning of the profiles.

include aerosols located in incomplete overlap zone of lidar. The NMMB/BSC-Dust model forecasted a dust event over the Dakar site with AOD values ranging from 0.8 to 1.6 at $550 \mathrm{~nm}$ for both day- and nighttime (Fig. 11). Unfortunately, no measurements could be obtained from the wind lidar. However, a sea breeze was observed at the ground level during daytime measurements. Back-trajectory analysis showed that during the daytime event, the sources of air masses that came to the observational site changed from north (coast of Mauritania) at $0.5 \mathrm{~km}$ to east (north-west of Mali) at $2.5 \mathrm{~km}$ (Fig. 12). Additionally, during the night, air masses were coming from the northeast direction (Sahara region) at all altitudes. The GARRLiC and Raman plus regularization aerosol retrievals for the day- and nighttime measurements are presented in Table 3.

GARRLiC single mode inversion was used because of the huge predominance of coarse mode particles. As in the previous event, daytime $r_{\mathrm{eff}}$ is high and equal to $2.0 \mu \mathrm{m}$, and the value decreases to $0.9 \mu \mathrm{m}$ at night. The daytime columnintegrated RRI is close to $1.59 \pm 0.02$ and stays rather stable at nighttime $(1.54 \pm 0.06)$. The IRI slightly decreases during the daytime from $0.004 \pm 0.002$ to $0.002 \pm 0.001$ in the UV-near-infrared range and is close to $0.008 \pm 0.004$ at the nighttime. The GARRLiC SSA increases from $0.85 \pm 0.03$ to $0.95 \pm 0.01$ in UV-near-infrared range. The maximum of SD is shifted to higher radii (Fig. 13). However, in general, RRI, IRI, SSA, and SD retrieved by GARRLiC are quite comparable to AERONET values. However, $r_{\text {eff }}$ and particle sphericity differ. AERONET $r_{\text {eff }}$ is equal to $1.6 \mu \mathrm{m}$ and sphericity 
Table 3. Aerosol properties during the dust event over the Dakar site on 10 April 2015. The LR values marked by ** were retrieved by the LIRIC algorithm. Only the values given for all the wavelengths refer to the column-integrated property. Day: AOD $440 \mathrm{~nm} \approx 1.53 \pm 0.04$; $\alpha \approx 0.02 \pm 0.01$. Night: AOD $532 \mathrm{~nm} \approx 0.83 ; \alpha \approx 0$ by Raman.

\begin{tabular}{|c|c|c|c|c|c|c|c|c|c|c|c|}
\hline \multirow[b]{2}{*}{$\lambda(\mathrm{nm})$} & \multicolumn{5}{|c|}{ GARRLiC } & \multirow{2}{*}{$\begin{array}{l}\text { AERONET } \\
\text { LR (sr) }\end{array}$} & \multirow{2}{*}{$\begin{array}{l}\text { Raman (day) } \\
\text { LR (sr) }\end{array}$} & \multicolumn{4}{|c|}{ Raman and regularization (night) } \\
\hline & $r_{\text {eff }}(\mu \mathrm{m})$ & Sph $\%$ & RRI & IRI & LR (sr) & & & $r_{\text {eff }}(\mu \mathrm{m})$ & RRI & IRI & LR (sr) \\
\hline 355 & & & 1.60 & 0.004 & 20 & $70 * *$ & $\sim 25$ & & & & $\sim 59$ \\
\hline 440 & & & 1.60 & 0.003 & 17 & 62 & & & & & \\
\hline 532 & f: 0.2 & & 1.60 & 0.003 & 14 & $49 * *$ & $\sim 23$ & & & & $\sim 50$ \\
\hline 675 & c: 2.4 & $57 \%$ & 1.60 & 0.002 & 13 & 39 & & 0.9 & 1.54 & 0.008 & \\
\hline 870 & $\mathrm{t}: 2.0$ & & 1.59 & 0.002 & 12 & 32 & & & & & \\
\hline 1020 & & & 1.58 & 0.002 & 13 & 31 & & & & & \\
\hline 1064 & & & 1.58 & 0.002 & 13 & $30 * *$ & & & & & \\
\hline
\end{tabular}
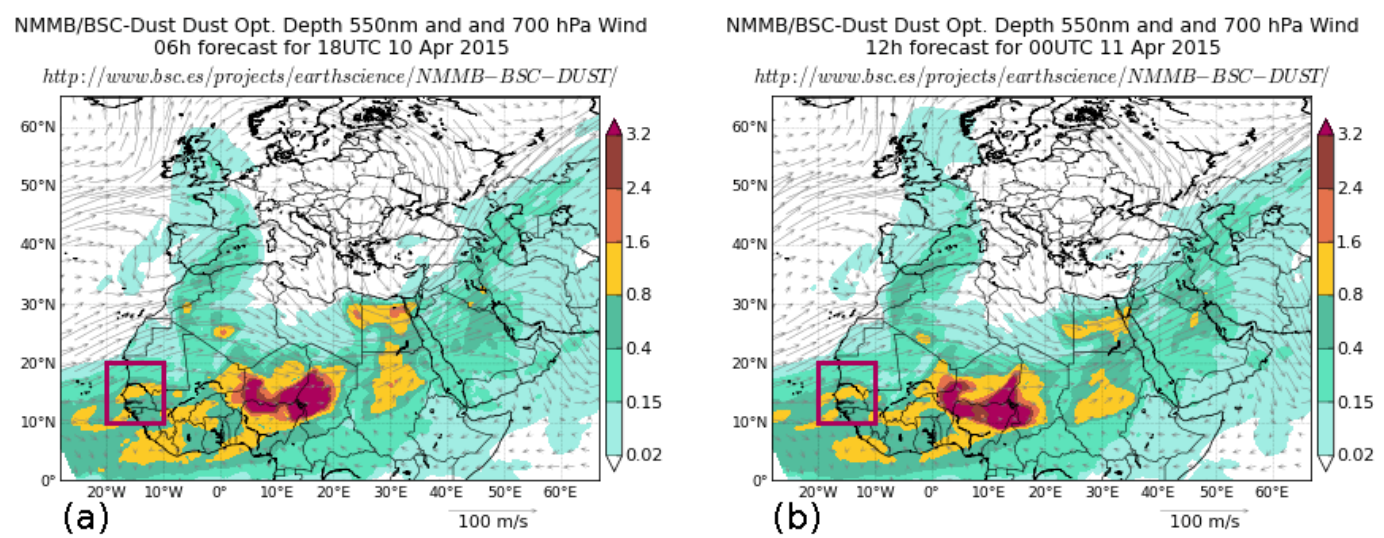

Figure 11. NMMB/BSC-Dust model results over Africa and Europe on 10 April 2015. AOD values forecasted by the model ranged from 0.8 to 1.6 at $550 \mathrm{~nm}$. (a) 18:00 UTC, 10 April; (b) 00:00 UTC, 11 April.

$\sim 0 \%$, while the GARRLiC algorithm retrieved $2.0 \mu \mathrm{m}$ for $r_{\text {eff }}$ and $57 \%$ of sphericity particles.

Volume concentration profiles are presented in Fig. 14. Because of different AOD values and altitudes of the boundary layer, day- and nighttime $V$ obtained using different methods are not comparable. The LIRIC and GARRLiC daytime $V$ are different, especially below $2 \mathrm{~km}$, which can be explained by LIRIC usage of both $532 \mathrm{~nm}$ parallel and perpendicular signals whereas GARRLiC used total backscattered signal only. However, obtained uncertainties are high and data are overlapped. Extinction profiles (Fig. 15) at all wavelengths are close to each other in respect to the retrieval algorithm. Differences between LRs retrieved by the algorithms are very high, but, nevertheless, $\sigma$ profiles of different algorithms do not have such high differences. The GARRLiC LRs for 355 and $532 \mathrm{~nm}$ are $20 \pm 11$ and $14 \pm 21$ respectively. The Raman LR values at $532 \mathrm{~nm}$ increase from $\sim 23$ to $\sim 50$ sr over the day- to nighttime measurement time frame, and LR at $355 \mathrm{~nm}$ also increases from $\sim 25$ to $\sim 59$ sr (Fig. 16). Such an increase in LR from day- to nighttime measurements can be explained by the contribution of marine particles during the daytime (i.e. sea-breeze effect). Particle depolarization is lower during daytime (29\%) than during nighttime (32\%).
The Raman $\alpha_{\text {ext }}$ profile at $355 / 532 \mathrm{~nm}$ is close to 0 and does not change with altitude (this is not shown in the figures). The profile of the effective radius retrieved with regularization decreases from 1.2 to $0.6 \mu \mathrm{m}$ at the altitude range of $1-4.5 \mathrm{~km}$. Regularization RRI and IRI profiles remain stable through all altitudes, and column-integrated values, which are presented in Table 3, have been taken as averaged values.

The volume concentration profile at $2 \mathrm{~km}$ is much higher during the daytime measurements than the one obtained at night. For comparison with NMMB/BSC-Dust model results, the mass concentration profiles were obtained (Fig. 14). Similar to the previous event, the particle density was taken to be equal to $2.6 \mathrm{~g} \mathrm{~cm}^{-3}$ according to the NMMB/BSCDust model for GARRLiC result. And total LIRIC mass concentration defined as sum of fine and coarse aerosol modes values. The obtained mass concentration profiles at $2 \mathrm{~km}$ are close to $1225 \pm 400$ and $1020 \pm 90 \mu \mathrm{g} \mathrm{m}^{-3}$ for GARRLiC and LIRIC, respectively. This is at least 2 times higher in comparison with the value produced by the NMMB/BSC-Dust model $\left(\sim 550 \mu \mathrm{g} \mathrm{m}^{-3}\right)$. The calculated Raman nighttime mass concentration $\left(310 \pm 60 \mu \mathrm{g} \mathrm{m}^{-3}\right)$ shows good agreement with the NMMB/BSC-Dust model $\left(\sim 300 \mu \mathrm{g} \mathrm{m}^{-3}\right)$ at $2 \mathrm{~km}$. 


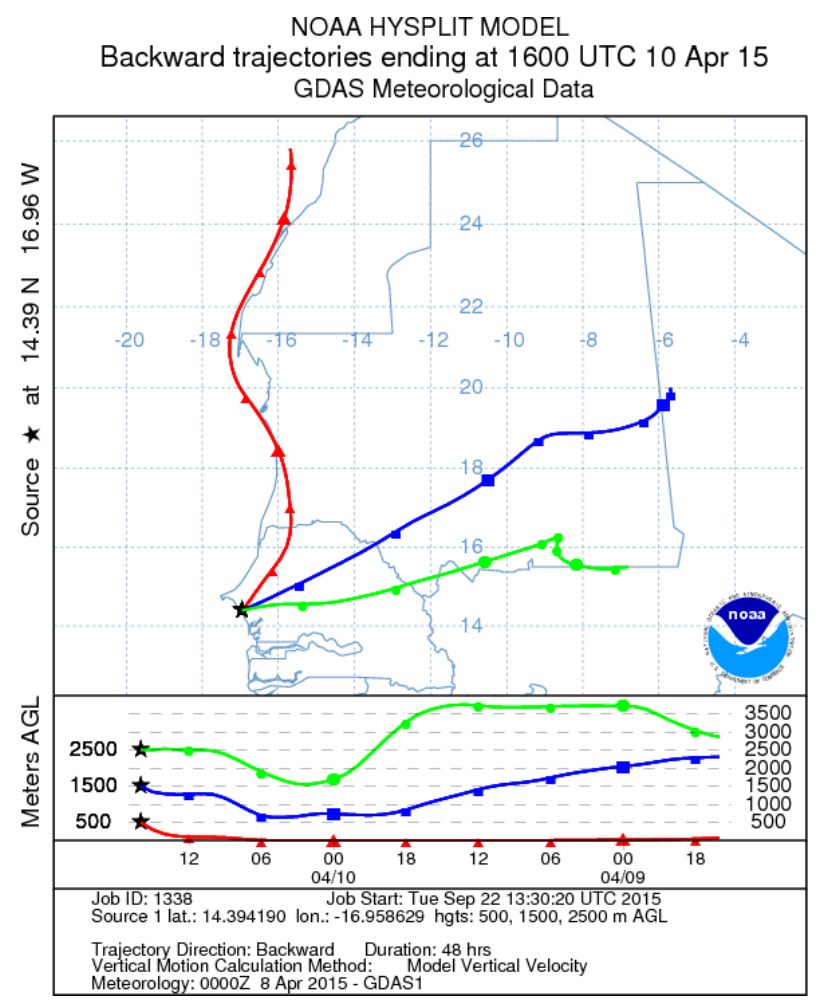

Figure 12. Backward trajectories of air masses for an event over the Dakar site on 10 April 2015.

Raman and GARRLiC daytime LRs indicate very likely the measurements of marine particles, but at the same time the depolarization ratio indicates at mineral dust. The GAR$\mathrm{RLiC}$ results are more consistent with mineral dust, but at the same time the retrieved sphericity (57\%) is too high for dust and LR values at all wavelengths are too low.

Such a complex event, which includes several types of particles with similar radii, can cause difficulties in retrieving, interpreting, and comparing the results. The GARRLiC and LIRIC height-resolved aerosol properties are incompatible with the NMMB/BSC-Dust $V$ and Raman $\sigma$ profiles. That is why, to avoid inconsistencies between the results of different methods, GARRLiC should be only implemented in cases (i) where a single aerosol type is present or (ii) when the investigated aerosols can be separated into two different types of fine and coarse modes.

\section{Conclusions}

As mentioned previously, the main objective of this article is to compare aerosol properties retrieved by different algorithms. This helps to know to what extent these algorithms can be used in a complementary way for long-term day-night aerosol observations and data processing.

Three dust events were selected from LILAS measurements. The first event over Lille on 30 March 2014 was char-

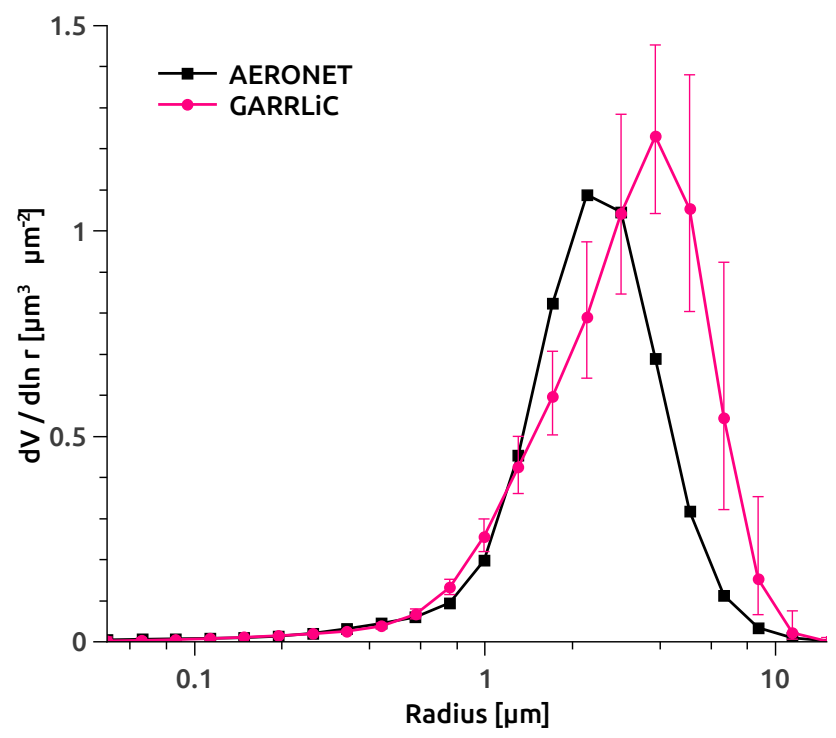

Figure 13. GARRLiC (pink) and AERONET (black) SD for 10 April 2015 (16:11 UTC) over the Dakar site (AOD $440 \mathrm{~nm} \approx 1.53 \pm$ $0.04 ; \alpha \approx 0.02 \pm 0.01)$.

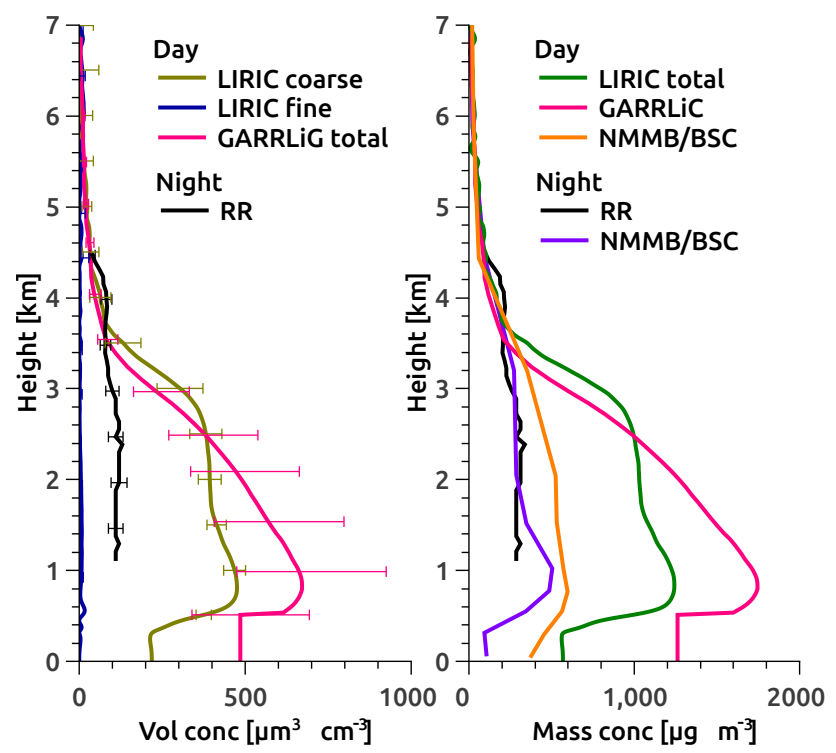

Figure 14. Volume (Vol conc) and mass (Mass conc) concentration profiles for an event over the Dakar site on 10 April 2015. The abbreviation RR corresponds to $V$ retrieved by using Raman and regularization algorithms.

acterized by transported mineral dust particles from the Saharan region. Three different layers of aerosols were observed: (i) assumed urban particles up to $2.5 \mathrm{~km}$, (ii) dust layer in the altitude range of 2.5 to $6 \mathrm{~km}$, and (iii) cirrus clouds with a negligible AOD impact at heights of 11 to $12 \mathrm{~km}$.

The second and third events over Dakar were characterized by a layer consisting of a dust and marine (small contribution) aerosol mixture during the daytime and only dust 


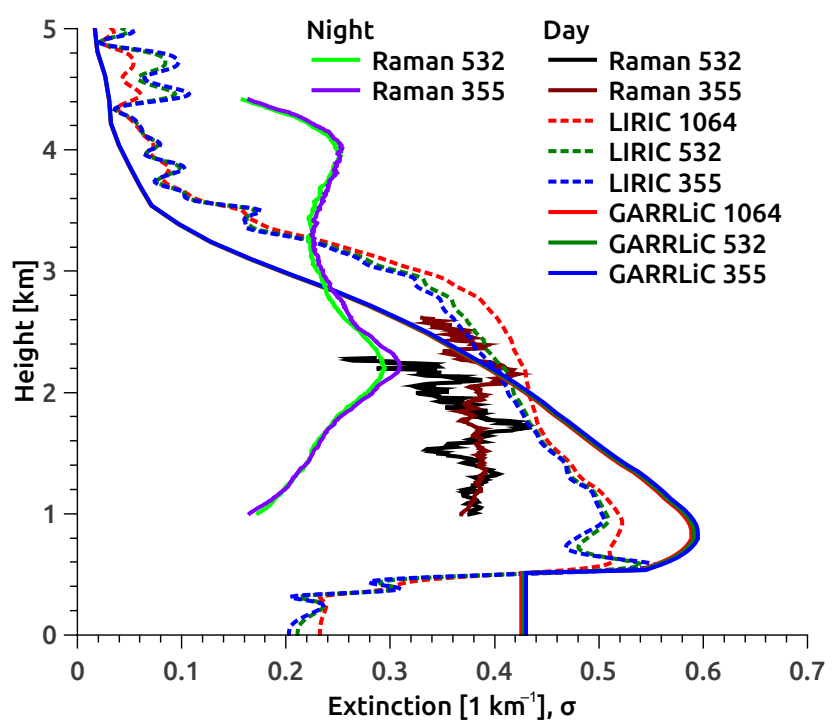

Figure 15. Raman, LIRIC, and GARRLiC extinction profiles during the day $(\mathrm{AOD} 440 \mathrm{~nm} \approx 1.53 \pm 0.04 ; \alpha \approx 0.02 \pm 0.01)$ and night (AOD $532 \mathrm{~nm} \approx 0.83 ; \alpha \approx 0$ by Raman) on 10 April 2015 .

particles during the nighttime. In both cases, AOD values decrease over the day- to nighttime measurement time frame, and, therefore, it was not possible to compare the day- and nighttime $\sigma$. GARRLiC, LIRIC, and Raman daytime $\sigma$ profiles are in agreement on 29 March. However, $\sigma$ profiles retrieved by the same algorithms on 10 April differ. The latter was a more complex event with different types of particles in the same size range. Development, such as introducing depolarization profile into the GARRLiC algorithm, should enhance the algorithm and make it possible to distinguish aerosols with different shapes inside one mode. In both dust cases, $r_{\text {eff }}$ were found to be higher during daytime in comparison with the nighttime cases. Raman LRs increased over the day- to nighttime measurement time frame, which could be caused by the absent of marine particles at night. However, depolarization ratios were always indicative of dust particles. GARRLiC LR values were always lower than the ones obtained by LIRIC and Raman. Also, GARRLiC sphericity was always higher than the one obtained by AERONET. Also, the presence of marine particles should decrease RRI values during the day, but daytime RRI values were higher in comparison with the nighttime ones. However, daytime IRI values were lower in comparison with the ones obtained at night, which agrees with the presence of marine particles, which absorb less than dust particles. These features indicate the challenges in description of optical properties of nonspherical particles in backscattering, on top of possible inconsistencies between the retrieval algorithms used herein. The studies by (Müller et al., 2013), (Wiegner et al., 2009), and (Kokhanovsky, 2015) suggest that the difficulties with reproduction of the observations relate to inaccuracies in the spheroidal model in reproduction of scattering properties in

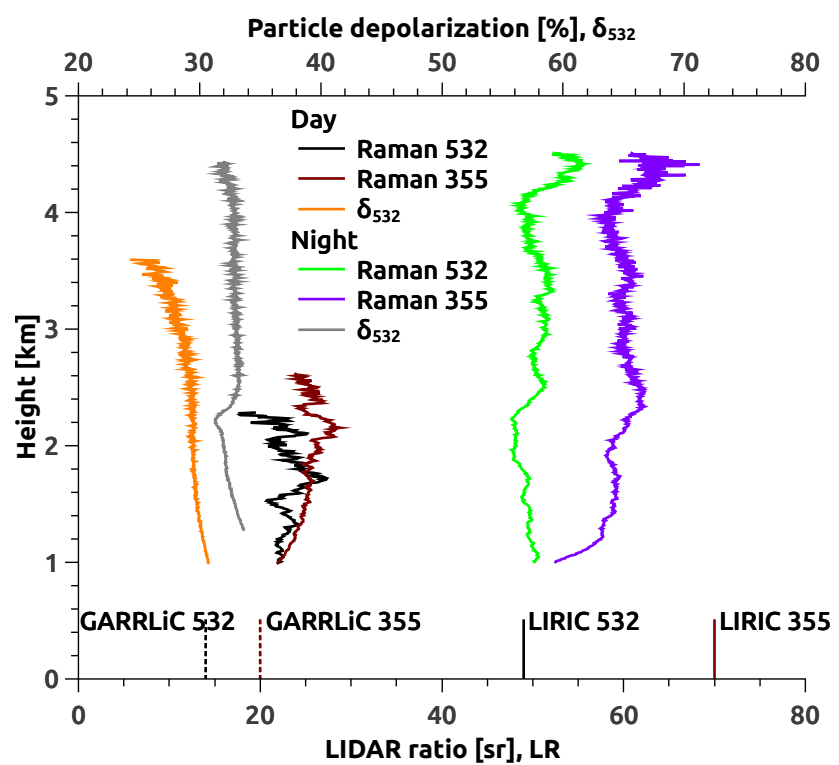

Figure 16. Lidar ratio and depolarization ratio during day- and nighttime measurements for an event on 10 April 2015 over the Dakar site. GARRLiC and LIRIC LR column-integrated values are shown at the beginning of the profiles.

backwards direction. However, those studies are focused on observations of desert dust particle depolarization that were not used in GARRLiC and LIRIC analysis of this study. At the same time, it is worth mentioning that recent research by (Veselovskii et al., 2016) has reported very encouraging agreement of spheroidal model with dust observations. More events should be analysed in order to distinguish the inconsistencies between the algorithms. The second phase of the SHADOW2 campaign will be taking place in DecemberJanuary 2016.

In future studies, it will be interesting to select morning measurements excluding see-breeze and marine particles. GARRLiC development (for instance, by incorporating the Raman technique and/or depolarization profile into the code) will make it possible to distinguish vertically resolved aerosol optical properties more accurately, i.e. improved extinction and volume concentration profiles. After such improvements, similar studies should be carried out and, again, the algorithm results should be compared to determine whether they are able to complement each other for long-term day-night measurements.

\section{Data availability}

AERONET data for Dakar and Lille instrumentation sites are available at http://aeronet.gsfc.nasa.gov/. Lidar data available at http://www-loa.univ-lille1.fr/index.php/observation/ lidar.html. 


\section{The Supplement related to this article is available online at doi:10.5194/amt-9-3391-2016-supplement.}

Acknowledgements. The research leading to these results has received funding from European Union's Horizon 2020 research and innovation programme under grant agreement no. 654109 within the ACTRIS project. The authors acknowledge Diaollo Aboubacry and Thierno Ndiaye from IRD (Institute pour la Recherche et le Développement) at Mbour, Dakar, Senegal, and the CaPPA project for the its support. The authors acknowledge Sara Basart and the BSC-CNS (Barcelona Supercomputing Center/Centro Nacional de Supercomputación) team for providing modelled dust concentration profiles.

Edited by: V. Amiridis

Reviewed by: three anonymous referees

\section{References}

Ansmann, A., Riebesell, M., and Weitkamp, C.: Measurement of atmospheric aerosol extinction profiles with a Raman lidar, Opt. Lett., 15, 746-748, doi:10.1364/OL.15.000746, 1990.

Ansmann, A., Tesche, M., Seifert, P., Groß, S., Freudenthaler, V., Apituley, A., Wilson, K. M., Serikov, I., Linné, H., Heinold, B., Hiebsch, A., Schnell, F., Schmidt, J., Mattis, I., Wandinger, U., and Wiegner, M.: Ash and fine-mode particle mass profiles from EARLINET-AERONET observations over central Europe after the eruptions of the Eyjafjallajökull volcano in 2010, J. Geophys. Res.-Atmos., 116, d00U02, doi:10.1029/2010JD015567, 2011.

Ansmann, A., Seifert, P., Tesche, M., and Wandinger, U.: Profiling of fine and coarse particle mass: case studies of Saharan dust and Eyjafjallajökull/Grimsvötn volcanic plumes, Atmos. Chem. Phys., 12, 9399-9415, doi:10.5194/acp-12-9399-2012, 2012.

Balis, D., Amiridis, V., Nickovic, S., Papayannis, A., and Zerefos, C.: Optical properties of Saharan dust layers as detected by a Raman lidar at Thessaloniki, Greece, Geophys. Res. Lett., 31, doi:10.1029/2004GL019881, 2004.

Barnaba, F. and Gobbi, G. P.: Lidar estimation of tropospheric aerosol extinction, surface area and volume: Maritime and desert-dust cases, J. Geophys. Res.-Atmos., 106, 3005-3018, doi:10.1029/2000JD900492, 2001.

Binietoglou, I., Basart, S., Alados-Arboledas, L., Amiridis, V., Argyrouli, A., Baars, H., Baldasano, J. M., Balis, D., Belegante, L., Bravo-Aranda, J. A., Burlizzi, P., Carrasco, V., Chaikovsky, A., Comerón, A., D’Amico, G., Filioglou, M., Granados-Muñoz, M. J., Guerrero-Rascado, J. L., Ilic, L., Kokkalis, P., Maurizi, A., Mona, L., Monti, F., Muñoz-Porcar, C., Nicolae, D., Papayannis, A., Pappalardo, G., Pejanovic, G., Pereira, S. N., Perrone, M. R., Pietruczuk, A., Posyniak, M., Rocadenbosch, F., Rodríguez-Gómez, A., Sicard, M., Siomos, N., Szkop, A., Terradellas, E., Tsekeri, A., Vukovic, A., Wandinger, U., and Wagner, J.: A methodology for investigating dust model performance using synergistic EARLINET/AERONET dust concentration retrievals, Atmos. Meas. Tech., 8, 3577-3600, doi:10.5194/amt-83577-2015, 2015.
Böckmann, C., Mironova, I., Müller, D., Schneidenbach, L., and Nessler, R.: Microphysical aerosol parameters from multiwavelength lidar, J. Opt. Soc. A, 22, 518-528, 2005.

Chaikovsky, A., Dubovik, O., Pappalardo, G., Wandinger, U., Apituley, A., Alados-Arbroledas, L., Pappayannis, A., and Pietruczuk, A.: Algorithm and Software for the retrieval of vertical aerosol porperties using combined Lidar/Radiometer data: dissemination in AERLINET, 339-402, 26th International Laser Radar Conference, 2012, Porto Heli, Greece, 2012.

Chaikovsky, A., Dubovik, O., Holben, B., Bril, A., Goloub, P., Tanré, D., Pappalardo, G., Wandinger, U., Chaikovskaya, L., Denisov, S., Grudo, J., Lopatin, A., Karol, Y., Lapyonok, T., Amiridis, V., Ansmann, A., Apituley, A., Allados-Arboledas, L., Binietoglou, I., Boselli, A., D’Amico, G., Freudenthaler, V., Giles, D., Granados-Muñoz, M. J., Kokkalis, P., Nicolae, D., Oshchepkov, S., Papayannis, A., Perrone, M. R., Pietruczuk, A., Rocadenbosch, F., Sicard, M., Slutsker, I., Talianu, C., De Tomasi, F., Tsekeri, A., Wagner, J., and Wang, X.: Lidar-Radiometer Inversion Code (LIRIC) for the retrieval of vertical aerosol properties from combined lidar/radiometer data: development and distribution in EARLINET, Atmos. Meas. Tech., 9, 1181-1205, doi:10.5194/amt-9-1181-2016, 2016.

Collaud Coen, M., Weingartner, E., Schaub, D., Hueglin, C., Corrigan, C., Henning, S., Schwikowski, M., and Baltensperger, U.: Saharan dust events at the Jungfraujoch: detection by wavelength dependence of the single scattering albedo and first climatology analysis, Atmos. Chem. Phys., 4, 2465-2480, doi:10.5194/acp4-2465-2004, 2004.

Draxler, R. R. and Rolph, G. D.: HYSPLIT (HYbrid Single-Particle Lagrangian Integrated Trajectory) Model access via NOAA ARL READY Website, available at: http://ready.arl.noaa.gov/ HYSPLIT.php (last access: July 2016), 2015.

Dubovik, O. and King, M. D.: A flexible inversion algorithm for retrieval of aerosol optical properties from Sun and sky radiance measurements, J. Geophys. Res.-Atmos., 105, 20673-20696, doi:10.1029/2000JD900282, 2000.

Dubovik, O., Holben, B., Eck, T. F., Smirnov, A., Kaufman, Y. J., King, M. D., Tanré, D., and Slutsker, I.: Variability of Absorption and Optical Properties of Key Aerosol Types Observed in Worldwide Locations, J. Atmos. Sci., 59, 590-608, doi:10.1175/15200469(2002)059<0590:VOAAOP>2.0.CO;2, 2002.

Dubovik, O., Herman, M., Holdak, A., Lapyonok, T., Tanré, D., Deuzé, J. L., Ducos, F., Sinyuk, A., and Lopatin, A.: Statistically optimized inversion algorithm for enhanced retrieval of aerosol properties from spectral multi-angle polarimetric satellite observations, Atmos. Meas. Tech., 4, 975-1018, doi:10.5194/amt-4975-2011, 2011.

Freudenthaler, V.: EARLINET-ASOS NA3, Internal LIDAR checkup procedures, Tech. rep., available at: http://www.actris.net/Portals/97/Publications/quality\% 20standards/lidar/QA-InternalCheckups_version_121017b.pdf (last access: July 2016), 2007.

Freudenthaler, V.: The telecover test: A quality assurance tool for the optical part of a LIDAR system, available at: http://epub.ub.uni-muenchen.de/12958/1/ILRC24-2008-S01P_ 30_Freudenthaler_Poster.pdf (last access: July 2016), 2008.

Freudenthaler, V.: EARLINET Quality Assurance - NA3, available at: http://www.actris.net/Portals/97/Publications/quality\% 
20standards/lidar/QA-InternalCheckups_version_121017b.pdf (last access: July 2016), 2010.

Freudenthaler, V., Böckmann, C., Bösenberg, J., and Pappalardo, G.: European Aerosol Research LIDAR Network - advanced sustainable observation system (EARLINET-ASOS), Plans for quality assurance, available at: http://www.meteo.physik. uni-muenchen.de/ st212fre/ILRC23/Freudenthaler.pdf, last access: July 2016.

Freudenthaler, V., Esselborn, M., Wiegner, M., Heese, B., Tesche, M., Ansmann, A., Müller, D., Althausen, D., Wirth, M., Fix, A., Ehret, G., Knippertz, P., Toledano, C., Gasteiger, J., Garhammer, M., and Seefeldner, M.: Depolarization ratio profiling at several wavelengths in pure Saharan dust during SAMUM 2006, Tellus B, 61, 165-179, doi:10.1111/j.1600-0889.2008.00396.x, 2009.

Goloub, P. and Holben, B.: available at: http://aeronet.gsfc. nasa.gov/cgi-bin/type_one_station_opera_v2_new?site= Lille\&nachal $=2 \&$ level $=3 \&$ place_code $=10$, last access: July 2016.

Goloub, P., Podvin, T., Blarel, L., Veselovskii, I., and Tanre, D.: available at: http://www-loa.univ-lille1.fr/Instruments/lidar/ calendriers/newcal_2015_shadows.php, last access: July 2016.

Giannakaki, E., Balis, D. S., Amiridis, V., and Zerefos, C.: Optical properties of different aerosol types: seven years of combined Raman-elastic backscatter lidar measurements in Thessaloniki, Greece, Atmos. Meas. Tech., 3, 569-578, doi:10.5194/amt-3569-2010, 2010.

Granados-Muñoz, M. J., Guerrero-Rascado, J. L., Bravo-Aranda, J. A., Navas-Guzmán, F., Valenzuela, A., Lyamani, H., Chaikovsky, A., Wandinger, U., Ansmann, A., Dubovik, O., Grudo, J. O., and Alados-Arboledas, L.: Retrieving aerosol microphysical properties by Lidar-Radiometer Inversion Code (LIRIC) for different aerosol types, J. Geophys. Res.-Atmos., 119, 4836-4858, doi:10.1002/2013JD021116, 2014.

Groß, S., Tesche, M., Freudenthaler, V., Toledano, C., Wiegner, M., Ansmann, A., Althausen, D., and Seefeldner, M.: Characterization of Saharan dust, marine aerosols and mixtures of biomassburning aerosols and dust by means of multi-wavelength depolarization and Raman lidar measurements during SAMUM 2, Tellus B, 63, 706-724, 2011.

Haustein, K., Pérez, C., Baldasano, J. M., Jorba, O., Basart, S., Miller, R. L., Janjic, Z., Black, T., Nickovic, S., Todd, M. C., Washington, R., Müller, D., Tesche, M., Weinzierl, B., Esselborn, M., and Schladitz, A.: Atmospheric dust modeling from meso to global scales with the online NMMB/BSC-Dust model - Part 2: Experimental campaigns in Northern Africa, Atmos. Chem. Phys., 12, 2933-2958, doi:10.5194/acp-12-2933-2012, 2012.

Heymsfield, A. J. and Platt, C.: A parameterization of the particle size spectrum of ice clouds in terms of the ambient temperature and the ice water content, J. Atmos. Sci., 41, 846-855, 1984.

Holben, B. N., Eck, T. F., Slutsker, I., Smirnov, A., Sinyuk, A., Schafer, J., Giles, D., and Dubovik, O.: Aeronet's Version 2.0 quality assurance criteria, Proc. SPIE, 6408, 64080Q-64080Q14, doi:10.1117/12.706524, 2006.

Klett, J. D.: Stable analytical inversion solution for processing lidar returns, Appl. Opt., 20, 211-220, doi:10.1364/AO.20.000211, 1981.

Klett, J. D.: Lidar inversion with variable backscatter/extinction ratios, Appl. Opt., 24, 1638-1643, doi:10.1364/AO.24.001638, 1985.
Kokhanovsky, A. A.: Light Scattering Reviews 9, Praxis Publishing, 2015.

Lopatin, A., Dubovik, O., Chaikovsky, A., Goloub, P., Lapyonok, T., Tanré, D., and Litvinov, P.: Enhancement of aerosol characterization using synergy of lidar and sun-photometer coincident observations: the GARRLiC algorithm, Atmos. Meas. Tech., 6, 2065-2088, doi:10.5194/amt-6-2065-2013, 2013.

Mortier, A., Goloub, P., Podvin, T., Deroo, C., Chaikovsky, A., Ajtai, N., Blarel, L., Tanre, D., and Derimian, Y.: Detection and characterization of volcanic ash plumes over Lille during the Eyjafjallajökull eruption, Atmos. Chem. Phys., 13, 3705-3720, doi:10.5194/acp-13-3705-2013, 2013.

Müller, D., Wandinger, U., and Ansmann, A.: Microphysical particle parameters from extinction and backscatter lidar data by inversion with regularization: theory, Appl. Opt., 38, 2346-2357, doi:10.1364/AO.38.002346, 1999.

Müller, D., Mattis, I., Wandinger, U., Ansmann, A., Althausen, D., and Stohl, A.: Raman lidar observations of aged Siberian and Canadian forest fire smoke in the free troposphere over Germany in 2003: Microphysical particle characterization, J. Geophys. Res.-Atmos., 110, d17201, doi:10.1029/2004JD005756, 2005.

Müller, D., Ansmann, A., Mattis, I., Tesche, M., Wandinger, U., Althausen, D., and Pisani, G.: Aerosol-type-dependent lidar ratios observed with Raman lidar, J. Geophys. Res.-Atmos., 112, d16202, doi:10.1029/2006JD008292, 2007.

Müller, D., Ansmann, A., Freudenthaler, V., Kandler, K., Toledano, C., Hiebsch, A., Gasteiger, J., Esselborn, M., Tesche, M., Heese, B., Althausen, D., Weinzierl, B., Petzold, A., and von Hoyningen-Huene, W.: Mineral dust observed with AERONET Sun photometer, Raman lidar, and in situ instruments during SAMUM 2006: Shape-dependent particle properties, J. Geophys. Res.-Atmos., 115, d11207, doi:10.1029/2009JD012523, 2010.

Müller, D., Veselovskii, I., Kolgotin, A., Tesche, M., Ansmann, A., and Dubovik, O.: Vertical profiles of pure dust and mixed smoke-dust plumes inferred from inversion of multiwavelength Raman/polarization lidar data and comparison to AERONET retrievals and in situ observations, Appl. Opt., 52, 3178-3202, doi:10.1364/AO.52.003178, 2013.

Nicolae, D., Nemuc, A., Müller, D., Talianu, C., Vasilescu, J., Belegante, L., and Kolgotin, A.: Characterization of fresh and aged biomass burning events using multiwavelength Raman lidar and mass spectrometry, J. Geophys. Res.-Atmos., 118, 2956-2965, 2013.

Pérez, C., Haustein, K., Janjic, Z., Jorba, O., Huneeus, N., Baldasano, J. M., Black, T., Basart, S., Nickovic, S., Miller, R. L., Perlwitz, J. P., Schulz, M., and Thomson, M.: Atmospheric dust modeling from meso to global scales with the online NMMB/BSC-Dust model - Part 1: Model description, annual simulations and evaluation, Atmos. Chem. Phys., 11, 1300113027, doi:10.5194/acp-11-13001-2011, 2011.

Petzold, A., Veira, A., Mund, S., Esselborn, M., Kiemle, C., Weinzierl, B., Hamburger, T., Ehret, G., Lieke, K., and Kandler, K.: Mixing of mineral dust with urban pollution aerosol over Dakar (Senegal): impact on dust physico-chemical and radiative properties, Tellus B, 63, 619-634, 2011.

Pitari, G., Di Genova, G., Coppari, E., De Luca, N., Di Carlo, P., Iarlori, M., and Rizi, V.: Desert dust transported over Europe: Lidar observations and model evaluation of the ra- 
diative impact, J. Geophys. Res.-Atmos., 120, 2881-2898, doi:10.1002/2014JD022875, 2015.

Rolph, G. D.: Real-time Environmental Applications and Display sYstem (READY) Website, available at: http://ready.arl.noaa.gov (last access: July 2016), 2015.

Shcherbakov, V.: Regularized algorithm for Raman lidar data processing, Appl. Opt., 46, 4879-4889, doi:10.1364/AO.46.004879, 2007.

Trouillet, V. and Flamant, P. H.: Impact of cirrus cloud ice crystal shape and size on multiple scattering effects: application to spaceborne and airborne backscatter lidar measurements during LITE mission and E LITE campaign, Geophys. Res. Lett., 26, 2203-2206, 1999.

Veselovskii, I., Kolgotin, A., Griaznov, V., Müller, D., Wandinger, U., and Whiteman, D. N.: Inversion with regularization for the retrieval of tropospheric aerosol parameters from multiwavelength lidar sounding, Appl. Opt., 41, 3685-3699, doi:10.1364/AO.41.003685, 2002.

Veselovskii, I., Kolgotin, A., Griaznov, V., Müller, D., Franke, K., and Whiteman, D. N.: Inversion of multiwavelength Raman lidar data for retrieval of bimodal aerosol size distribution, Appl. Opt., 43, 1180-1195, doi:10.1364/AO.43.001180, 2004.

Veselovskii, I., Kolgotin, A., Müller, D., and Whiteman, D. N.: Information content of multiwavelength lidar data with respect to microphysical particle properties derived from eigenvalue analysis, Appl. Opt., 44, 5292-5303, doi:10.1364/AO.44.005292, 2005.

Veselovskii, I., Dubovik, O., Kolgotin, A., Lapyonok, T., Di Girolamo, P., Suma, D., Whiteman, D. N., Mishchenko, M., and Tanré, D.: Demonstration of Aerosol Property Profiling by Multiwavelength Lidar under Varying Relative Humidity Conditions, J. Geophys. Res., 115, 1543-1557, doi:10.1029/2010JD014139, 2010a.

Veselovskii, I., Dubovik, O., Kolgotin, A., Lapyonok, T., Di Girolamo, P., Summa, D., Whiteman, D. N., Mishchenko, M., and Tanré, D.: Application of randomly oriented spheroids for retrieval of dust particle parameters from multiwavelength lidar measurements, J. Geophys. Res.-Atmos., 115, D21203, doi:10.1029/2010JD014139, 2010b.

Veselovskii, I., Whiteman, D. N., Korenskiy, M., Suvorina, A., and Pérez-Ramírez, D.: Use of rotational Raman measurements in multiwavelength aerosol lidar for evaluation of particle backscattering and extinction, Atmos. Meas. Tech., 8, 41114122, doi:10.5194/amt-8-4111-2015, 2015.
Veselovskii, I., Goloub, P., Podvin, T., Bovchaliuk, V., Derimian, Y., Augustin, P., Fourmentin, M., Tanre, D., Korenskiy, M., Whiteman, D. N., Diallo, A., Ndiaye, T., Kolgotin, A., and Dubovik, O.: Retrieval of optical and physical properties of African dust from multiwavelength Raman lidar measurements during the SHADOW campaign in Senegal, Atmos. Chem. Phys., 16, 70137028, doi:10.5194/acp-16-7013-2016, 2016.

Wagner, J., Ansmann, A., Wandinger, U., Seifert, P., Schwarz, A., Tesche, M., Chaikovsky, A., and Dubovik, O.: Evaluation of the Lidar/Radiometer Inversion Code (LIRIC) to determine microphysical properties of volcanic and desert dust, Atmos. Meas. Tech., 6, 1707-1724, doi:10.5194/amt-6-1707-2013, 2013.

Wandinger, U., Ansmann, A., Reichardt, J., and Deshler, T.: Determination of stratospheric aerosol microphysical properties from independent extinction and backscattering measurements with a Raman lidar, Appl. Opt., 34, 8315-8329, doi:10.1364/AO.34.008315, 1995.

Wang, Y., Sartelet, K. N., Bocquet, M., Chazette, P., Sicard, M., D’Amico, G., Léon, J. F., Alados-Arboledas, L., Amodeo, A., Augustin, P., Bach, J., Belegante, L., Binietoglou, I., Bush, X., Comerón, A., Delbarre, H., García-Vízcaino, D., GuerreroRascado, J. L., Hervo, M., Iarlori, M., Kokkalis, P., Lange, D., Molero, F., Montoux, N., Muñoz, A., Muñoz, C., Nicolae, D., Papayannis, A., Pappalardo, G., Preissler, J., Rizi, V., Rocadenbosch, F., Sellegri, K., Wagner, F., and Dulac, F.: Assimilation of lidar signals: application to aerosol forecasting in the western Mediterranean basin, Atmos. Chem. Phys., 14, 12031-12053, doi:10.5194/acp-14-12031-2014, 2014.

Weitkamp, C.: Lidar: range-resolved optical remote sensing of the atmosphere, Springer series in optical sciences, 2005.

Wiegner, M., Gasteiger, J., Kandler, K., Weinzierl, B., Rasp, K., Esselborn, M., Freudenthaler, V., Heese, B., Toledano, C., Tesche, M., and Althausen, D.: Numerical simulations of optical properties of Saharan dust aerosols with emphasis on lidar applications, Tellus B, 61, 180-194, 2009. 